\title{
Study on electrochemical principle and characteristic curve of nickel hydrogen battery for mine
}

\author{
Gaojian $\operatorname{Ren}^{1}$ \\ ${ }^{1}$ China Coal Technology and Engineering Group Chongqing Research Institute, Chongqing, 400039, China;
}

\begin{abstract}
As a kind of high-energy secondary battery, mining Ni MH battery is very suitable for mine backup power because of its advantages of high capacity, high power, no pollution, long cycle life, strong charging and discharging ability and high safety. This paper mainly introduces the electrochemical reaction of $\mathrm{Ni} \mathrm{MH}$ battery under normal operation, overcharge and over discharge, introduces the types and components of Ni MH battery, describes the change curve of charging and discharging terminal voltage with time under different conditions, analyzes the self discharge situation of Ni MH battery under different conditions, and analyzes the cycle life and safety of Ni MH battery. The software and hardware design of battery intelligent management and SOC estimation analysis provide the basic basis.
\end{abstract}

\section{Introduction}

The key technology research and implementation of intelligent management of mining backup power supply based on $\mathrm{Ni} \mathrm{MH}$ battery needs to study the electrochemical principle and characteristic curve of $\mathrm{Ni}$ $\mathrm{MH}$ battery, so as to provide theoretical basis for SOC estimation and battery management of backup power supply.

\section{Reaction principle of $\mathrm{Ni} \mathrm{MH}$ battery}

Nickel oxide is used as anode, hydrogen storage alloy as cathode and potassium hydroxide as electrolyte. There are also two kinds of $\mathrm{Ni} \mathrm{MH}$ alloy, which are ni-2-based alloy and ni-5-based alloy. At present, AB5 is the mainstream alloy for negative electrode of $\mathrm{Ni} \mathrm{MH}$ battery.

\subsection{Electrochemical reaction for normal operation of $\mathrm{Ni} \mathrm{MH}$ battery}

Under normal charge and discharge conditions, the internal electrochemical reaction of $\mathrm{Ni} \mathrm{MH}$ battery is as follows:

Negative reaction:

$$
\mathrm{H}_{2} \mathrm{O}+\mathrm{M}+e \underset{\text { disch } \arg e}{\stackrel{c h \arg e}{\Leftrightarrow}} \mathrm{MH}+\mathrm{OH}^{-}
$$

Positive reaction:

$$
\mathrm{OH}^{-}+\mathrm{Ni}(\mathrm{OH})_{2} \underset{\text { disch } \arg e}{\stackrel{c h \arg e}{\Leftrightarrow}} \mathrm{NiOOH}+\mathrm{H}_{2} \mathrm{O}+\mathrm{e}
$$

Total reaction:

$$
\mathrm{M}+\mathrm{Ni}(\mathrm{OH})_{2} \underset{\text { disch arge }}{\stackrel{\text { charge }}{\Leftrightarrow}} \mathrm{MH}+\mathrm{NiOOH}
$$

It can be seen from the electrochemical reaction formula that no soluble ions are produced in the whole process, which ensures good stability of the battery. At the same time, the electrolyte is not consumed or produced. Therefore, the Ni MH battery can be free of maintenance and completely enclosed.

\subsection{Electrochemical reaction of $\mathrm{Ni} \mathrm{MH}$ battery under overcharge and over discharge}

When the $\mathrm{Ni} \mathrm{MH}$ battery is overcharged, the electrochemical reactions at the two poles of the battery are as follows:

Negative reaction:

$$
2 \mathrm{H}_{2} \mathrm{O}+\mathrm{O}_{2}+4 e \rightarrow 4 \mathrm{OH}^{-}
$$

Positive reaction:

$$
4 \mathrm{OH}^{-} \rightarrow \mathrm{O}_{2} \uparrow+2 \mathrm{H}_{2} \mathrm{O}+4 e
$$

It can be seen from the 1-4 and 1-5 reaction formulas that when the Ni MH battery has been overcharged, the reaction of the battery is electrolyzed water, and the $\mathrm{O} 2$ generated from the positive electrode reaches the negative electrode, and then generates $\mathrm{OH}-$, the total reaction has no consumption of potassium hydroxide and water, and the total amount of battery remains unchanged.

In the case of over discharge of Ni MH battery, the reaction between the two poles of the battery is as follows:

Negative reaction:

$$
2 \mathrm{OH}^{-}+\mathrm{H}_{2} \rightarrow 2 \mathrm{H}_{2} \mathrm{O}+2 e
$$

Positive reaction:

\footnotetext{
$\overline{{ }^{a} \text { Corresponding author: fjcdnf@qq.com }}$
} 


$$
2 e+2 \mathrm{H}_{2} \mathrm{O} \rightarrow \mathrm{H}_{2} \uparrow+2 \mathrm{OH}^{-}
$$

It can be seen from the reaction formula that when the $\mathrm{Ni}$ MH battery is over discharged, the positive electrode produces $\mathrm{H} 2$, and the negative electrode oxidizes the $\mathrm{H} 2$ produced by the positive electrode into water. The total reaction is zero, but the battery will have reverse polarity. The voltage at the positive side is lower than that at the negative side.

$\mathrm{Ni}$ MH battery often adopts the design that the positive capacity is less than the negative capacity. This is because with the aging of the battery, the catalytic ability of the alloy decreases, and the $\mathrm{H} 2$ and $\mathrm{O} 2$ produced in the electrochemical reaction process can not be completely eliminated. Therefore, the charging and discharging resistance of the Ni MH battery is reduced. After the design of the positive capacity less than the negative capacity, the reserved capacity can be reduced or even avoided from overcharging The internal pressure of hydrogen storage alloy increases to avoid the oxidation of hydrogen storage alloy under the condition of over discharge.

\section{Characteristic curve of Ni MH battery}

\subsection{Charging characteristics under different conditions}

The charging characteristics of $\mathrm{Ni}$ MH battery are affected by many factors, including charging rate, temperature and time, and the charging efficiency is also affected by these factors. In general, the constant current charging is carried out in the range of $1 \mathrm{C}$, and the charging and discharging efficiency is the best when the temperature is between $0 \sim 40{ }^{\circ} \mathrm{C}$ and about $25^{\circ} \mathrm{C}$. If the battery is charged at too low temperature or high temperature for a long time, the performance of the battery will be seriously damaged. At the same time, repeated overcharging of $\mathrm{Ni} \mathrm{MH}$ battery will also damage the battery life, and there is the possibility of explosion. The capacity of Ni MH battery is different under different conditions, which will change with the change of conditions. If the maximum cut-off voltage is set too high, it will lead to overcharge. If the maximum cut-off voltage is set too low, it may lead to the failure of $\mathrm{Ni}$ MH battery to be fully charged. Therefore, the reasonable charging cut-off voltage under different conditions has a great impact on the Ni MH battery.

At $25{ }^{\circ} \mathrm{C}$ ambient temperature, the terminal voltage curve obtained by constant current charging at different charging rates for a single Ni MH battery is shown in Fig. 1 .

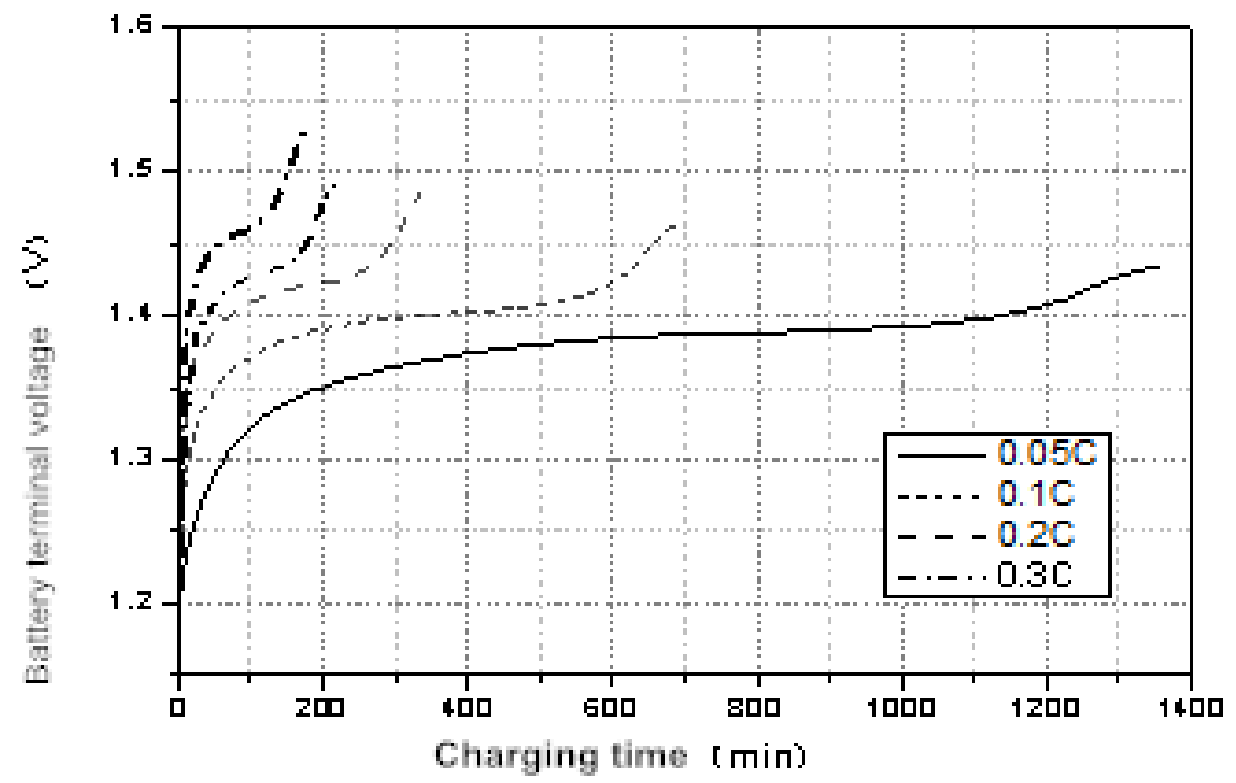

Fig. 1 At $25^{\circ} \mathrm{C}$ ambient temperature rechargeable nimh battery voltage of the monomer voltage curve

It can be seen from the above figure that the higher the charging rate, the higher the terminal voltage of the battery, the greater the slope of the terminal voltage rise, and the corresponding increase of the cut-off voltage at the highest point. When the battery continues to charge after reaching the cut-off voltage, the voltage will decrease. The greater the charging rate is, the greater the drop range will be. At the same time, the temperature will rise sharply.
At the same charging rate, different temperatures will also affect the terminal voltage of Ni MH battery. As shown in Fig. 2, 0.2C and $0.4 \mathrm{C}$ are respectively used to charge the single Ni MH battery at $25^{\circ} \mathrm{C}$ and $40{ }^{\circ} \mathrm{C}$. The change curve of the terminal voltage with time can be observed. It can be seen that the terminal voltage of the battery will vary with the temperature at the same charging rate, and the curve changes as follows The translation of the whole. At relatively low temperature, 
the higher the cut-off voltage corresponding to the full charge of $\mathrm{Ni} \mathrm{MH}$ battery is, the overall curve moves upward, and the amplitude of upward shift increases with the increase of charging rate.

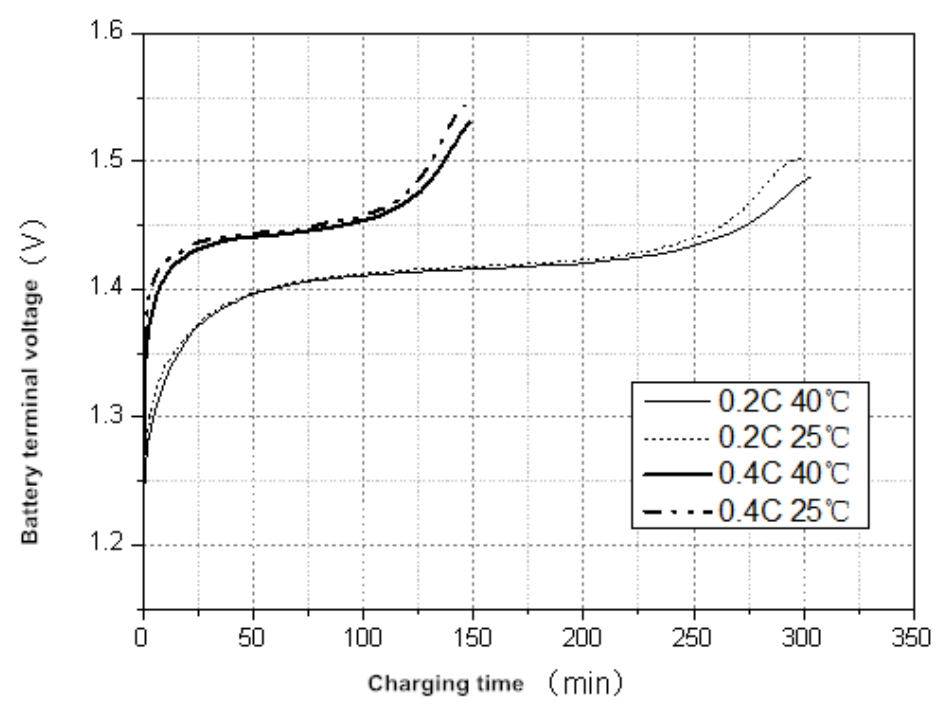

Fig.2 The change of the terminal voltage of single cell in different temperature conditions

\subsection{Discharge characteristics under different conditions}

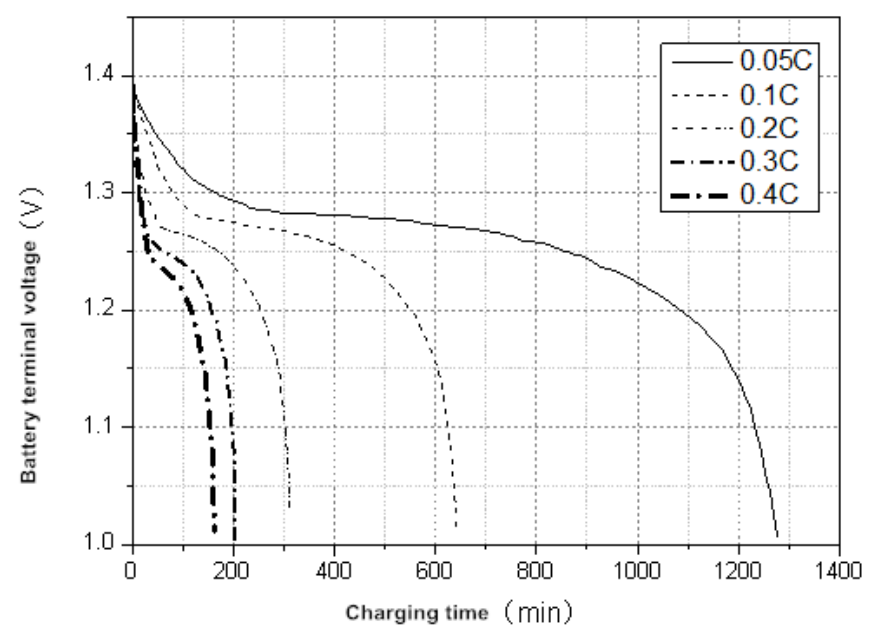

Fig.3 At $25^{\circ} \mathrm{C}$ ambient temperature down electric voltage of the nimh battery monomer voltage curve

In the constant current discharge of $\mathrm{Ni} \mathrm{MH}$ battery, the change curve of terminal voltage with time is also affected by many factors, such as discharge rate, temperature and so on. The lower the ambient temperature is, the higher the discharge rate is, the lower the discharge terminal voltage of $\mathrm{Ni} \mathrm{MH}$ battery will be reduced, and the discharge efficiency will also become worse. Generally, the maximum discharge rate of mining $\mathrm{Ni} \mathrm{MH}$ battery will not exceed $0.4 \mathrm{C}$. If the cut-off voltage of $\mathrm{Ni} \mathrm{MH}$ battery is set too high, the battery power can not be fully utilized, and the lower cut-off voltage will lead to over discharge of battery, which will seriously damage the battery performance. According to GBT 22084.2, the cut-off voltage is set at $1 \mathrm{~V}$.
Figure 3 shows the curve of terminal voltage versus time obtained by discharging a single $\mathrm{Ni}$ MH battery at a fixed discharge rate at $25{ }^{\circ} \mathrm{C}$. The discharge rates are $0.05 \mathrm{c}, 0.1 \mathrm{C}, 0.2 \mathrm{C}, 0.3 \mathrm{C}$ and $0.4 \mathrm{C}$. It can be seen that the discharge curve of $\mathrm{Ni} \mathrm{MH}$ battery has a stable platform area, which is also the main working area of $\mathrm{Ni} \mathrm{MH}$ battery, basically within the range of $0.5 \mathrm{~V}$. Because of this characteristic, $\mathrm{Ni} \mathrm{MH}$ battery is especially suitable for the load which requires stable voltage, but it also increases the difficulty of SOC estimation. 


\section{Conclusion}

This paper mainly introduces the electrochemical reaction of $\mathrm{Ni} \mathrm{MH}$ battery under normal operation and overcharge and over discharge, introduces the types and components of $\mathrm{Ni} \mathrm{MH}$ battery, describes the change curve of charging and discharging terminal voltage with time under different conditions, and analyzes the self discharge situation of $\mathrm{Ni} \mathrm{MH}$ battery under different conditions, It provides the basis for the design of hardware and software of $\mathrm{Ni} \mathrm{MH}$ battery intelligent management and the estimation and analysis of SOC.

\section{Acknowledgement}

Special Fund Project for Scientific and Technological Innovation and Entrepreneurship of Tiandi Science \& Technology Co., Ltd (Project No.: 2020-TD-QN012);

\section{References}

1. Chen Zhijun, Li Yangying. (2017) Neural Network BP Algorithm Improvement and Performance Analysis [J]. Software Guide,16 (10) 39-41.

2. L. Xu, J. Wang, and Q. Chen. (2012) "Kalman filtering state of charge estimation for battery management system based on a stochastic fuzzy neural network battery model." [J].Energy Conversion and Management, 53:33-39

3. Y. Zhang, X. M. Cheng, Y. Q. Fang, et al. (2013) On SOC estimation of lithium-ion battery packs based EKF[C]. Proceedings of the 32nd Chinese Control Conference. Xi'an, China, July26-28, 7668-7673

4. Hu X, Sun F, Zou Y. (2013) Comparison between Two Model-Based Algorithms for Li-ion Battery SOC Estimation in Electric Vehicles[J]. Simulation Modelling Practice \& Theory, 34(4): 1-11.

5. Li B, Zhao Y. (2014) Estimation of Power Battery SOC Based on Peukert Equation and Extended

6. Kalman Filtering[J]. China Mechanical Engineering, 25(6): 848-851.

7. Huang Shangqing, Zhao Zhiyong, Sun Libo.(2017) Improvement of BP neural network algorithm [J]. Science and Technology Innovation Guide, (20) 146 -147 .

8. Zhang Li. Research of Fuzzy Prediction Algorithm in SOC Estimation of New Energy Vehicles[J]. Journal of Electronic Measurements \& Sinstrument, 2011, 25(4):315-319.

9. ZHU C B,COLEMAN M,HURLEYWG.State of charge determination in a lead-acid battery: combined EMF estimation and Ah-balance approach[C].The 35th Annual Power Electronics Specialists Conference.2014:1908 1914

10. LIN Chengtao, CHEN Quanshi, WANG Junping, et al. Improved Ah counting method for state of charge estimation of electric vehicle batteries[J].J Tsinghua Univ:Sc\&Tech,2016,46( 2) :46 49. 